https://doi.org/10.48009/2_iis_2005_197-203

\title{
EVALUATING THE IMPACT FACTOR: A CITATION STUDY FOR INFORMATION TECHNOLOGY JOURNALS
}

\author{
Ms. Kara J. Gust, Michigan State University, gustk@msu.edu
}

\begin{abstract}
Throughout the course of scholarly communication, citation data has become a prominent tool for evaluating the network of journals and scholarly literature in a variety of disciplines, and for faculty promotion in the tenure system. This paper will discuss the citation data collected and a number of other factors as they relate to the network of information technology/computer information systems journals. It will also provide analysis of how journals in the field of CIS rank and how the Journal of Computer Information Systems ranks among its peer journals. It will also explore how today's world of rapidly changing technology, including electronic access to journals through the Web, has become a factor to consider in citation data and analysis.
\end{abstract}

Keywords: citation analysis, journal citation reports, information technology, impact factors

\section{INTRODUCTION}

In the early 1970s, Garfield recognized that "as a communication system, the network of journals that play a paramount role in the exchange of scientific and technical information is little understood" [1]. The scholarly community was missing a "map of the journal network as a whole" and therefore a systematic and statistical way of measuring journal citations was needed [1]. This need was filled when in 1971, the Institute for Scientific Information (ISI) started collecting and analyzing references in journals across the sciences, and then eventually in the social sciences and other disciplines, publishing these in its Science Citation Index and Social Sciences Citation Index.

By gathering journal references, ISI was also able to produce a number of statistical measures of journals in its exclusive Journal Citation Reports (JCR), providing a way for scholars, librarians, and publishers to evaluate the impact of a journal in its own discipline or across disciplines based upon a number of criteria. Journal Citation Reports provides statistics and citation data on over 6,100 international science journals and about 1,800 international social sciences journals through its Science Edition and Social Sciences Edition. Data gathered in JCR includes total cites, impact factor, immediacy index, articles published, cited half-life and citing half-life, cited journal and citing journal listings, and source data. Today, ISI provides online access to JCR and its other citation indexes through its Web of Science subscription database.

The use of citation data gathered by ISI, most prominently that of the impact factor, has been studied by a number of scholars and needs to be carefully evaluated when using it as a basis of a journal's credibility and impact in its field. In evaluating the use of citation data for journal analysis, this paper will primarily look at the calculation of the impact factor and immediacy index, as well as other influencing factors, among information technology journals, more specifically among computer information systems (CIS) journals. 


\section{EVALUATING JCR DATA FOR COMPUTER INFORMATION SYSTEMS JOURNALS}

The following section will explain in greater detail which citation data is collected in JCR and how it is calculated, with primary emphasis on the impact factor and immediacy index among CIS journals. To compare the data for CIS journals, all were selected from the subject category of COMPUTER SCIENCE, INFORMATION SYSTEMS in the 2003 Science Edition of JCR.

\section{The Impact Factor}

The journal impact factor (IF) is a measure of the frequency with which the average article in a journal has been cited in a particular year. It is calculated by dividing the number of citations in the current year (2003) to articles published in the two previous years (e.g., 2001-2002 by the total number of articles published in the two previous years (e.g., 2001-2002). For example, in 2003, the IF for the Journal of Computer Information Systems (JCIS) is calculated as follows:

\begin{tabular}{|c|c|c|c|}
\hline Cites in 2003 to articles published in: & $\begin{array}{l}2002=2 \\
2001=8 \\
\end{array}$ & Number of articles published in: & $\begin{array}{l}2002=68 \\
2001=57 \\
\end{array}$ \\
\hline & Im: & & um: \\
\hline
\end{tabular}

Calculation: $\underline{\text { Cites to recent articles } \quad 10=\mathbf{0 . 0 8 0}}$ Number of recent articles 125

Table 1. Selected CIS Journals Ranked According To Impact Factor

\begin{tabular}{lll} 
Rank & \multicolumn{1}{c}{ Journal Title } & Impact Factor \\
\hline 1 & VLDB Journal: The International Journal of Very Large Databases & 4.545 \\
2 & IEEE Network & 3.871 \\
3 & ACM Transactions on Information Systems & 3.533 \\
77 & Journal of Computer Information Systems & 0.080
\end{tabular}

The comparison of JCIS to the top three highest-ranking journals is a rather difficult one on a number of grounds. When comparing journals even within one discipline it is important to consider a number of other factors such as strength and size of the publishing body or organization including its perceived public reputation and years it has existed, and the subject classifications assigned to the individual journals by ISI versus that of other classifying bodies such as the Library of Congress (LC), not to mention the content of the individual articles themselves.

The publishing body or organization can have a significant impact on the perceived relevance of a journal in its discipline. For CIS journals, the VLDB Journal and the ACM Transactions on Information Systems are both publications of the Association for Computing Machinery (ACM), the well-established professional organization in computing and information technology, since 1947, with over 80,000 members. It produces over 40 publications, including journals, magazines, and Transactions series. In fact, of the 78 CIS journals included in ISI, ACM authors at least seven of them (of which 4 are ranked in the top 15 in IF). Ranked second is IEEE Network, a publication of the Institute of Electrical and Electronics Engineers (IEEE), with over 365,000 members and over 120 publications and a history dating back to the 1880s. Of the 78 CIS journals in ISI, IEEE authors at least eight of them (of which 4 are ranked in the top 15 in IF). In comparison, IACIS, formed in 1960, has an international membership of 700, founded mostly for computer information systems educators. So the mission, purpose, and focus of an 
organization can also be important considerations that factor into the overall influence of their publications.

In addition, when comparing the relevance of journals in their respective disciplines, it is also essential to examine their many subject classifications. Many of those journals listed under COMPUTER SCIENCE, INFORMATION SYSTEMS are also assigned additional subject headings by ISI. As is often the case with commercial indexes/databases, these subject headings do not correlate with LC subject headings, as shown in Table 2.

Table 2. Comparison of ISI to LC Subject Headings for CIS Journals

\begin{tabular}{|c|c|c|c|}
\hline Rank & Journal Title & ISI Subject Heading(s) & LC Subject Heading(s) \\
\hline 1 & VLDB Journal & $\begin{array}{l}\text { - Computer Science -- } \\
\text { Information Systems } \\
\text { - Hardware \& Architecture }\end{array}$ & $\begin{array}{l}\text { - Database management } \\
\text { - Data structures (Computer } \\
\text { science) } \\
\text { - Databases }\end{array}$ \\
\hline 2 & IEEE Network & $\begin{array}{l}\text { - Computer Science -- } \\
\text { Hardware \& Architecture } \\
\text { - Engineering -- Electrical \& } \\
\text { Electronic } \\
\text { - Telecommunications }\end{array}$ & - Computer networks \\
\hline 3 & $\begin{array}{l}\text { ACM Transactions on } \\
\text { Information Systems }\end{array}$ & $\begin{array}{l}\text { - Computer Science -- } \\
\text { Information Systems }\end{array}$ & $\begin{array}{l}\text { - Electronic data processing } \\
\text { - Information storage and retrieval } \\
\text { systems } \\
\text { - Information retrieval }\end{array}$ \\
\hline 77 & $\begin{array}{l}\text { Journal of Computer } \\
\text { Information Systems }\end{array}$ & $\begin{array}{l}\text { - Computer Science -- } \\
\text { Information Systems }\end{array}$ & $\begin{array}{l}\text { - Electronic data processing - } \\
\text { Study and teaching }\end{array}$ \\
\hline
\end{tabular}

This can be important in determining the particular content and subject matter of the journal. By selecting only those journals in ISI given the heading of COMPUTER SCIENCE, INFORMATION SYSTEMS and cross-referencing those journals listed in OCLC WorldCat with the headings of ELECTRONIC DATA PROCESSING, only seven journals remain. Based upon these classifications, it is difficult to rank JCIS among its peer journals at first glance and by looking at IF alone.

\section{Other Considerations When Using the Impact Factor}

The methodology of the impact factor has been debated numerous times and evaluated through a number of different studies. Many have argued that the impact factor should not be used exclusively for evaluating research and the validity of a journal. Seglen gives an analysis of several problems associated with the impact factor and cautions against its use for evaluating journals [7]. Moed concludes that the impact factor calculation introduces an inherent bias and suggests the use of an "adjusted impact factor" to correct this [6]. Others note the nature of each field of research, as well as sociological and psychological influences, can also affect impact factor measures [3-5]. Table 3 provides a summary of some issues these studies have revealed when evaluating the impact factor of journals. Based upon these studies and considerations developed by looking at impact factors among CIS journals, it is clear that the IF cannot be the 
total measure of a journal's relevance in its discipline. There are many other statistical measures and sociological influences at work.

Table 3. Issues Concerning the Impact Factor

1. Citation Rates of Individual Articles: Because both the highly cited and less-frequently cited articles are included in the IF calculation, articles cited less frequently have equal weight in the calculation.

2. Article Length: Longer articles typically generate many citations and give a higher IF. No corrections are made for the length of the articles cited. Therefore, journals that publish longer articles will generally receive a higher IF.

3. Types of Citations: In calculating the IF, citations to letters, editorials, and reports are included in the number of citations to a particular journal (numerator), however only review and research articles are included in the number of recent articles published by the journal (denominator). This can work to inflate the IF of journals with many letters or editorials to those journals that instead have more research articles.

4. Publication Lags: Since the IF is determined by calculating citations to articles published only within the last two years, those journals with short publication lags allow for more current citations and therefore can lead to a higher IF. This can heavily favor those disciplines where research can be conducted and published quickly.

5. Self Citations: Since articles in journals tend to cite articles from the same journal this process of self-citation can lead to more citations and a higher IF, even though other publications may not be citing them as frequently.

6. Author Preferences: An author may or may not choose to publish in a particular journal based upon its IF. Other influences can be the desired audience, the fairness of the refereeing process, and the likelihood of acceptance [2].

\section{Immediacy Index}

In addition to the IF, JCR also calculates the immediacy index (II), which is a measure of how quickly the average article in a journal is cited (see Table 4). The II is calculated by dividing the number of citations to articles published in a given year by the number of articles published in that year. In 2003, the immediacy index for JCIS is calculated as:

$$
\text { Calculation: } \frac{\text { Cites in } 2003 \text { to articles published in } 2003}{\text { Number of articles published in } 2003=}=\frac{1}{59}=\mathbf{0 . 0 1 7}
$$

Table 4. Selected CIS Journals Ranked According to Immediacy Index

\begin{tabular}{lll} 
Rank & Journal Title & Immediacy Index \\
\hline 1 & IBM Systems Journal & 0.942 \\
2 & Annual Review Of Information Science And Technology & 0.909 \\
3 & Journal Of The American Medical Informatics Association & 0.794 \\
60 & Journal of Computer Information Systems & 0.017
\end{tabular}

Among CIS journals, it appears that the II does not necessarily correlate with the IF, as is the case in many disciplines. In fact, they do not follow in the same order in IF either. IBM Systems Journal ranks $14^{\text {th }}$ in IF, while the Annual Review of Information Science and Technology ranks $8^{\text {th }}$, and the Journal of the American Medical Informatics Association ranks $11^{\text {th }}$. 


\section{Considerations When Using the Immediacy Index}

As with using the IF, it is important to consider other factors when using the II as one measure of a journal's impact in its field. One of the greater influences on a journal's II is its publication schedule; journals that publish more frequently and earlier in the year have a greater chance of being cited more quickly than those that publish late in the year or infrequently. This seems to follow in the case of CIS journals as well; among the top 15 ranked according to II, 14 are published at least four times a year and eight are published more than four times a year. Another influence on II is the subject discipline of the journal. Some disciplines are very dynamic, have short publication lags, and produce higher immediacy indexes (as well as IFs) since their articles are quickly cited. In comparison to CIS journals, where the II is under 1 and the IF is around 4, journals in biochemistry and molecular biology produce an II around 6 with IFs of over 30 . Overall, ranking journals by their II can help to determine which journals are publishing "hot" articles or which are in rapidly changing and dynamic disciplines.

\section{Other JCR Data for Journal Evaluation}

In addition to ranking journals according to statistical measures, JCR also provides information that helps to evaluate journals according to the age of its references and articles cited, as well as its competitor journals. Table 5 summarizes those other measures, along with relative data for JCIS.

Table 5. Other JCR Citation Data Collected

1. Cited Half-Life and Citing Half-Life: Cited half-life calculates the age of the majority of cited articles published in a journal and the citing half-life calculates the majority of articles referenced by a journal. Rather than using these to evaluate the impact of a journal, these measures are most useful in making editorial policy changes and collection management decisions.

2. Cited Journal: Identifies publications that most frequently cite a particular journal. These cited journal listings can be useful in evaluating the network of journals in a particular discipline by showing how the various subjects of journals relate to one another along with identifying a journal's closest peer or competitor journals. The journals that cited JCIS the most from 1994-2003 are JCIS (15 self-citations), IEEE Transactions on Engineering Management (3 citations), Computers in Human Behavior (2 citations), Epilepsia (2 citations), International Journal of Information Technology and Decision Making (2 citations), Journal of Management Information Systems (2 citations). It is important to note the impact factors of these journals are relatively high, even though there are not as many citations.

3. Citing Journal: Lists the publications that were most frequently cited by the current journal. From 1994-2003, JCIS most frequently cited: MIS Quarterly (66 citations), Communications of the ACM (51 citations), Journal of Management Information Systems (50 citations), Management Science (31 citations), Information Systems (28 citations), and Decision Sciences (21 citations). The impact factors of these range from 1.4 to 3.3 .

So when assessing a journal's IF and II, it is a good idea to take into consideration its cited and citing journals to identify more clearly its closer competitors and/or if some articles are being cited in journals with higher impact factors. 


\section{Source Data and Article Counts}

The source data table in ISI provides insight as to the types of articles published in the current year by the journal, along with the total number of references contained in those articles, and the average number of references per article. Table 6 provides the source data for JCIS. When looking at overall article counts, it is important to note that ISI only includes original research and review articles; editorials, letters, news items, and meeting abstracts are not counted because they are not generally cited. However, as was previously discussed, editorials and letters, etc. are included in the total citation counts, which can influence IF. So the source data can be highly useful in considering the types of articles being cited along with the number of references for each type.

Table 6. Summary of Source Data for JCIS

Non-Review Articles

Articles Reference

(A)

57

Items (R)

1703

Ratio

(R/A)

29.9

Review Articles

Articles Reference Ratio

(A)

2
Items (R) (R/A)

222

111.0

\section{Combined}

Articles Reference Ratio

(A) Items (R) (R/A)

$59 \quad 1925 \quad 32.6$

THE IMPACT OF ELECTRONIC PUBLISHING/ACCESS ON CITATION DATA

With the rapidly changing technology and online environment, journal literature can be produced and accessed more quickly than ever before. Since journal literature is so much more readily available online through the Web and commercial subscription databases, and therefore can be cited more quickly, it can be expected that the IF and II of a journal will be impacted. Therefore, in determining the impact of a journal, along with evaluating citation data, it is essential to consider whether or not it is being indexed in commercial electronic databases. The following section will look at those journals with the highest IFs and IIs in CIS and compare their electronic availability through electronic databases and online full-text journal packages.

\section{Electronic Indexes/Databases for Computer Information Systems Journals}

Among the top 15 journals ranked according to IF and II in the field of CIS for 2003, all except three are indexed in at least 10 commercial databases, with the majority being indexed in well more than 20. All of these journals are also are available in online full-text journal packages, the most prevalent being through IEEE, ACM Digital Library, EBSCO, Gale, Elsevier ScienceDirect, Swets, ProQuest, and OCLC FirstSearch. The most common databases in which these journals are indexed are: Inspec, Compumath Citation Index, Computer Science Index, Computer Database, Current Contents, Information Science \& Technology Abstracts, LISA: Library \& Information Science Abstracts, Computing Reviews, Computer Abstracts, Science Citation Index, and Social Sciences Citation Index. By far, the most dominant being Inspec, Compumath Citation Index, and Computer Science Index. It is interesting to note, however, that IBM Systems Journal which ranks $1^{\text {st }}$ in II is also freely available on the Web. This could be one reason that it has such a high II even though it ranks $14^{\text {th }}$ in IF. The same is true for the Journal of the American Medical Informatics Association, which ranks $3^{\text {rd }}$ in II, but $11^{\text {th }}$ in IF.

Similar to its peer journals, JCIS is being indexed by at least 10 indexes: Compumath Citation Index, Computer Science Index, Inspec, Business Education Index, OCLC ArticleFirst, EBSCO Business Source Corporate, EBSCO Business Source Premier, and ProQuest (various packages). 
This is a very positive sign for JCIS as it is being indexed by some of the top indexes in its discipline.

\section{CONCLUSIONS}

When analyzing a journal's impact in its field of study, especially when being used to evaluate faculty publications for tenure and promotion, it is necessary to consider many factors such as the true subject nature of the journal, types and length of articles, and size and mission of the publishing organization, in addition to analyzing ISI journal citation data. The same is true for those journals in information technology/computer information systems. This paper presents a broad analysis of information technology journal citation data collected by ISI, but there are many other factors that need to be explored in future studies. To provide a better understanding of how JCIS compares to its closest peer journals in terms of impact factor, it would be helpful to look at only those seven journals that match the subject classifications of JCIS in ISI and OCLC WorldCat, analyzing the content and length of their articles, references, and statistical measures.

Further study on the immediacy index among these journals, in terms of their specific publication schedules would also be useful to editors in determining if editorial policy needs to be changed. It would also be helpful to determine how electronic access to CIS journals granted through electronic databases, as well as the free Web, is affecting their individual IIs. In addition, with the advancement of Web publishing, citations to journal articles are appearing more and more on Web pages and publications. Further study is needed to determine if this may cause the IFs and IIs of journals to be underrepresented in JCR, as these citations are not currently included in JCR.

With the inception of ISI's journal impact factors and citation data collection, it is possible to gain a better understanding of the network of scholarly journals and the impact on their disciplines. However, careful evaluation of these factors is still a necessary process in determining a journal for its validity, influence, and imprint on its discipline and in the world of scholarly communication.

\section{REFERENCES}

1. Garfield, E. (1972). Citation Analysis as a Tool in Journal Evaluation, Science, 178(4060), 471-479.

2. Gordon, M. D. (1984). How Authors Select Journals: A Test of the Reward Maximization Model of Submission Behaviour, Social Studies of Science, 14(1), 27-43.

3. Kokko, H., \& Sutherland, W. J. (1999). What Do Impact Factors Tell Us? Trends in Ecology \& Evolution, 14(10), 382-384.

4. Lange, L. L. (2002). The Impact Factor as a Phantom; Is There a Self-Fulfilling Prophecy Effect of Impact? Erroneous Impact Factor for Education Journal in Journal Citation Reports, Journal of Documentation, 58(2), 175-184.

5. Metcalfe, N. B. (1995). Serious Bias in Journal Impact Factors, Trends in Ecology \& Evolution, 10(11), 461.

6. Moed, H. F., Van Leeuwen, T. N., \& Reedijk, J. A New Classification System to Describe the Ageing of Scientific Journals and Their Impact Factor. Study of Journal Citation Reports and Science Citation Index, Journal of Documentation, 54(4), 387-429.

7. Seglen, P. O. (1997). Why the Impact Factor of Journals Should Not Be Used for Evaluating Research, British Medical Journal, 314(7079), 498-502. 